Copyright (C) 2021 by Cherkas Global University

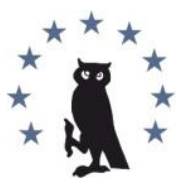

Published in the USA

Russkaya Starina

Has been issued since 2010.

E-ISSN: 2409-2118

2021. 12(2): 95-101

DOI: $10.13187 /$ rs.2021.2.95

https://rs.cherkasgu.press

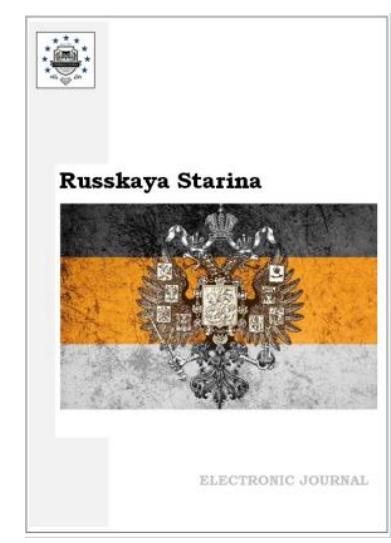

\title{
The Forgotten Poet of the Pushkin Era. Part 2
}

\author{
Marina Ch. Larionova ${ }^{a},{ }^{*}$ \\ ${ }^{a}$ Federal Research Centre the Southern Scientific Centre of the Russian Academy of Sciences, \\ Russian Federation
}

\begin{abstract}
V.I. Tumansky was considered an exclusively elegiac poet for a long time. However, Tumansky was an active participant in the literary life of the 1820-1830s and was in friendly relations with the future Decembrists. Staying in France, proximity to the French intelligentsia contributed to the formation of the socio-political views of Tumansky. During a European trip, he became close to V.K. Kühelbecker, who dedicated him the poem "To Tumansky", later renamed "To Achates", which reflected the poets' general attitude to the Greek struggle for independence. Under the influence of Kühelbecker, his famous lecture on the Russian language, given in the Athenaeum, Tumansky wrote the poem "The Holy Union of Peoples", which was a free translation of Berange's poem "La Saint-Alliance des peuples". The main idea of the poem is the unification of peoples as opposed to the "Holy Union" of monarchs. The anti-sefdom position of Tumansky is also close to the Decembrists. Tumansky's poem is utopian in nature and embodies the idea of the "golden age", as opposed to the real world, reality. Thus, we may confidently say that Tumansky was not a poet of the "pure art" as he actively participated in the public life of the 1820 .

Decembrists.

Keywords: Tumansky, Kühelbecker, "To Tumansky", "Holy Union of Peoples",

\section{1. Введение}

Долгое время В.И. Туманского считали исключительно элегическим поэтом. Начало этому положил В.Г. Белинский в статье «Русская литература в 1844 году». С.Н. Браиловский позже писал о Туманском: он «правдиво и искренно передал мысли и чувства, навеянные случаями его жизни и подчас столь далекие от всяких “злоб дня”» (Браиловский, 1890: 12). А потом и советский литературовед Б. Мейлах причислил Туманского к поэтам «чистого искусства», мотивируя это тем, что поэзия определяется им как дар богов, нечто неземное, чуждое действительности (Мейлах, 1937: 166). Однако Туманский был активным участником литературной жизни 20-30-х гг. XIX в. и состоял в дружеских отношениях с будущими декабристами. Восстановлению литературной репутации поэта и посвящена эта статья.
\end{abstract}

\section{2. Материалы и методы}

Материалом статьи стали стихотворения В.И. Туманского, публикации в журналах «Сын отечества», «Благонамеренный», воспоминания современников поэта, архивные источники. В качестве исследовательской позиции избраны биографический и культурно-

\footnotetext{
${ }^{*}$ Corresponding author

E-mail addresses: larionova@ssc-ras.ru (M.Ch. Larionova)
} 
исторический методы, которые позволяют на основе фактов биографии поэта «вписать» его в литературный и общественный контекст эпохи.

\section{3. Обсуждение и результаты}

В 1819 г. молодой поэт В.И. Туманский, чьи первые опыты уже обратили на себя внимание критики (Larionova, 2021), отправился за границу. Планы отъезда он строил еще в 1818 г., о чем писал в стихотворении «К друзьям детства»:

Я покидаю вас, о Лары красных дней!

О кров родительской, прелестной,

Где я в тиши расцвел, где я вкушал покой!

О други с доброю душой!

Я покидаю вас для дали неизвестной:

Так долг святой велит! (Туманский, 1912: 58)

О сильном влиянии заграничного путешествия на выработку общественной позиции писали многие современники поэта. Знакомство с европейской цивилизацией в ходе войны 1812 года, европейский дух свободы, проникший в Россию, и возникшие вследствие этого тайные общества, составленные умеренно монархические и радикально республиканские конституции привели к тому, что «до смерти Александра I либерализм стал уже достоянием каждого мало-мальски образованного человека», как писал декабрист А.П. Беляев (Беляев, 1882: 155).

Существует немного документальных сведений о пребывании Туманского за границей. Известно, что сначала он отправился в Вену с сенатором П.П. Щербатовым, а затем в Париж. Оттуда он сообщал в журнал «Благонамеренный» свои впечатления и знакомил читателей с новинками французского искусства. Так, в «Письме к издателю» он писал: «Выставление новых картин Французской школы в Королевский музеум наделало много шуму. Патриоты восхищаются множеством произведений любимых своих живописцев» (Туманский, 1819: 341). Лучшей картиной выставки Туманский счел «Пигмалиона и Галатею» Жироде: «Галатея - идеал божества. Легкость и нежность кисти, правильность и совершенство рисунков, выражение фигур отмечают сего славного художника-поэта» (Туманский, 1819: 342).

В «Письме к издателю» Туманский писал и о модном увлечении литографией. Стихотворение «Литография! ура!.», названное автором «водевиль», несмотря на шутливый тон, содержит идею, занимающую поэта с его первых литературных опытов. Это вопрос об отношении к войне:

Ныне наши булевары -

Вывеска кровавых дел:

Здесь пожар известных сел,

Дале - носятся гусары...

...Всюду Русские штыки

Впереди Австрийских пушек,

И карманные платки

Полны воинских игрушек,

Та, что девушка всегда,

Следуя последней моде,

Может даже и в народе,

Без малейшего стыда,

Смерть оплакивая брата,

Слезы отереть порой

Грудью Прусского солдата

Или Козака ногой (Туманский, 1819: 342-343).

Скрытый смысл стихотворения становится понятен, если вспомнить, что оно появилось в период создания Священного союза трех держав - России, Австрии и Пруссии. Все они названы Туманским: «русские штыки», «австрийские пушки», «прусский солдат». Священный союз призван был, прежде всего, подавлять всякое национальное революционное и освободительное движение. 
Пребывание во Франции, близость к французской интеллигенции способствовали становлению общественно-политических взглядов Туманского. Он слушал лекции Кузена и Араго в «Коллеж де Франс», бывал на заседаниях общества «Атеней», где часто выступал Бенжамен Констан. Имя Констана было необыкновенно популярно у молодых российских дворян, из которых вышли будущие декабристы. П.А. Вяземский позже вспоминал, какое влияние оказывали речи Констана на молодежь: «Политическая трибуна представителей французского народа была в то время богата великими и красноречивыми ораторами. Я, грешный человек, особенно любовался и увлекался красноречием ораторов левой стороны: Бенжамена Констана, генерала Фуа, Казимира Перье и других передовых сподвижников конституционного порядка» (Вяземский, 1879: XVII). Поэтому, когда в Париж в 1821 г. приехал В. Кюхельбекер, он нашел в Туманском единомышленника.

Кюхельбекер отправился за границу после скандала в Вольном обществе любителей российской словесности, вызванного его стихотворением «Поэты» на высылку Пушкина из Петербурга, в качестве секретаря А.Л. Нарышкина, который к этому времени оставил пост Главного директора Императорских театров. Туманский познакомился с Кюхельбекером, видимо, на заседаниях Общества в 1818 г. Известно, что Кюхельбекер в это время приносил своим ученикам-пансионерам стихи Туманского, в частности, его элегию «Монастырь» (Вацуро, 1975).

О пребывании Кюхельбекера в Париже сохранилось немногим больше достоверных сведений, чем о Туманском. Последний фигурирует в записях Кюхельбекера как «старый знакомый», а его имя стоит в одном ряду с Констаном (Тынянов, 1968: 308). Можно думать, что Туманский бывал вместе с Кюхельбекером в обществе «Атеней», где тот читал цикл лекций о русской литературе, общался с издателями либеральной газеты «Минерва», в том числе с Бенжаменом Констаном. О степени духовной и идейной близости двух молодых поэтов свидетельствует стихотворение Кюхельбекера «К Туманскому», названное в поздней редакции «К Ахатесу». Стихотворение написано в связи с начавшейся в марте 1821 г. борьбой греков за национальную независимость против турок. Оно датировано апрелем того же года.

Очевидная близость политических взглядов автора и адресата и позднее название «К Ахатесу» определили ошибочное мнение М.В. Нечкиной, что стихотворение посвящено А.С. Грибоедову. Несмотря на неверную адресацию, приведем аргументацию исследователя, поскольку она характеризует близость автора стихотворения и его адресата: «Ахатес - Fidus Achates - друг Энея, верность которого стала символическим образом дружеской верности. Кто другой в эти годы, кроме Грибоедова, мог получить от Кюхельбекера столь лестное и высокое наименование? <...> Поэтому мне представляется правдоподобным, что стихи "К Ахатесу" адресованы именно Грибоедову, тем более что только что исколесивший Европу Кюхельбекер вполне может подойти под сравнение с Энеем. Если это так, то естественно сделать вывод, что Грибоедов и Кюхельбекер были одних политических настроений в бурные 1821-1822 гг. и оба горели желанием принять участие в борьбе. <...>

Ахатес, Ахатес! ты слышишь ли глас,

Зовущий на битву, на подвиги нас? -

Мой пламенный юноша, вспрянь!

О друг, полетим на священную брань!

Кипит в наших жилах веселая кровь,

К бессмертью, к свободе пылает любовь,

Мы смелы, мы молоды: нам

Лететь к Марафонским, святым знаменам!» (Нечкина, 1977: 250).

Трудно более убедительно показать общность двух молодых поэтов. Верно все, за исключением имени адресата. Туманский, совсем недавно переводивший письма о Греции Савари, не мог равнодушно отнестись к греческим событиям. Вполне вероятно, что стихотворение «К Туманскому» стало результатом реальных бесед Туманского и Кюхельбекера, который собирался отправиться в Грецию сражаться за независимость, и даже, возможно, их намерений:

Нет, нет! - не останусь в бесчестном я сне;

Прости! - я сказал гробовой тишине:

Уж ждет меня сладостный бой; 
И пусть я паду, я паду как герой! -

и в вольность, и в славу, как я, ты влюблен;

Навек ты со мною душой сопряжен:

О друг, полетим же туда,

Туда, где восходит Свободы звезда! (Кюхельбекер, 1967: 620).

Название «К Ахатесу» возникло позже, вероятно, по возвращении поэта в Петербург. Адресат первоначальной редакции - реальный, конкретный человек: «Туманский, Туманский», «пламенный юноша», «мы Россы» и т.д. В «Ахатесе» он теряет индивидуальные черты, заменяется условным образом борца. При этом утраченной оказалась биографическая основа. «Ахатесы» - это все друзья лирического героя, все молодые, горячие его современники. В.Н. Касаткина заметила: В литературе появился новый романтический образ друзей - товарищей - сынов отечества - единомышленников, исповедующих возвышенные социальные, нравственные идеалы и реализующих свою высокую мораль в личных отношениях» (Касаткина, 1987: 103).

Под влиянием Кюхельбекера, его известной лекции о русском языке, прочитанной в «Атенее», Туманский написал стихотворение «Священный союз народов». Оно было прочитано на заседании Вольного общества любителей российской словесности 11 декабря 1822 г., одобрено большинством голосов, но не опубликовано. Текст этого стихотворения обнаружил В.Э. Вацуро и впервые опубликовал его в 1975 г. (Вацуро, 1975). Стихотворение представляет собой достаточно близкий перевод «La Saint-Alliance des peuples» Беранже, французского поэта, популярного в декабристском окружении. Политические стихи Беранже популяризировала и группа издателей журнала «Минерва» во главе с Б. Констаном. Туманский, не случайно выбрав для перевода именно это стихотворение, заострил и углубил его политическое содержание в связи с лекцией Кюхельбекера и антикрепостническими, антисамодержавными взглядами декабристов.

Основная идея стихотворения - объединение народов в противовес «Священному союзу» монархов. Декабристы отрицательно относились к участию России в «Священном союзе». П. Беляев, например, вспоминал: «много также нашему либерализму содействовали и внешние события, как-то: движение карбонариев, заключение Сильвио Пелико Австрией; отмененный поход нашей армии в Италию, показывающий, что и Россия была готова следовать за Австрией в порабощении народов» (Беляев, 1882: 155).

В отличие от Беранже Туманский назвал свое стихотворение гимном, гимном священному братству народов. Каждая строфа стихотворения заканчивается рефреном:

Народы - в славный круг! Как с братом брат, Воздвигните союз священный!

Мысль о единении народов с целью отстаивания своих человеческих и гражданских прав высказана и в лекции Кюхельбекера: «наступило время, когда для всех народов существенно взаимное... знание того, до какой степени развились среди них идеи, порожденные веком и просвещением, идеи, которые совершают в настоящую минуту великий переворот в духовной и гражданской жизни человеческого рода и пророчат еще более значительную и всеобщую перемену» (Кюхельбекер, 1954: 374).

Рассуждая о всеобщем равенстве, Туманский возвращается к идее «вечного мира», особенно усилившейся в Европе после наполеоновских войн. В 1820 г. в Париже было создано «Общество для установления всеобщего и вечного мира». Находясь в Париже, Туманский мог узнать об этом.

Войной изнеможенны

Германец, галл, и русский, и сармат!

Народы - в славный круг! Как с братом брат,

Воздвигните союз священный!

О смертные! вражда вас утомила,

И ваша жизнь - как вечный шум сует;

Равно землей судьба вас наделила

И всех равно вас греет солнца свет.

Но силою могущих увлечены,

Не видите вы милых сердцу трат.

Народы - в славный круг! Как с братом брат, 
Воздвигните союз священный!

Позиция Туманского во многом совпадает с мнением Кюхельбекера, выраженным в лекции: «насилие, принуждение никогда не искоренят из человеческой души то, что в них развил ход времени» (Кюхельбекер, 1954: 374). И далее: «Русские оставят в наследство истории другую славу, чем славу захватчика и разрушителя» (Кюхельбекер, 1954: 380). Туманский развивает эту мысль: в том случае, когда не будут доверять свою судьбу самовластным правителям:

Да ваша кровь не льется повсечастно

По манию насильственных знамен.

Земных светил явления мгновенны,

Сверкнув на миг, лишь миг они страшат.

Народы - в славный круг! Как с братом брат,

Воздвигните союз священный!

Близкой декабристам оказывается и антикрепостническая позиция Туманского. Кюхельбекер с горьким возмущением отзывался о современном состоянии России: «В России крепостное состояние еще не было установлено, русский крестьянин был свободным на своей усадьбе в те века, когда феодализм держал в рабстве земледельцев во всей остальной части Европы... Зачем Петр І... опозорил цепями рабства наших землепашцев... Сердце мое обливается кровью, и голос изменяет мне, когда я оплакиваю это несчастье моей родины...» (Кюхельбекер, 1954: 380). Об этом пишет и Туманский:

При зареве горящих ваших кущей

Воители, в свирепости своей,

Осмелились десницею могущей

Считать, клеймить, как собственность, людей.

Бессильные, на жертву обречены,

Вы цепь на цепь меняете стократ.

Народы - в славный круг! Как с братом брат,

Воздвигните союз священный!

На специфически русское, по сравнению с Беранже, содержание приведенной строфы справедливо указал В.Э. Вацуро в комментарии к этому стихотворению. Так, в первой строфе появляется сармат (у Беранже - бельгиец). Это прямая отсылка к насущному для России вопросу о Польше. В оригинале властители считают пленных, которых обрек им кровавый триумф. Народ - слабое стадо - бредет от тяжкого ярма к ярму бесчеловечному. Строка Туманского «считать, клеймить, как собственность, людей» не передает мысль оригинала о подсчете пленных, но воспринимается в контексте русской антикрепостнической поэзии. Кроме того, уподобление «народ - стадо» невозможно для Туманского. Он передает метафору Беранже традиционным «высоким» поэтизмом в духе гражданской лирики: «на жертву обречены, вы цепь на цепь меняете стократ» (Вацуро, 1975: 279).

К моменту написания «Священного союза народов» Туманский определенно был знаком и с антикрепостническими стихотворениями Пушкина. «Вольность» и «Деревня» получили широкое распространение. Картина рабства, нарисованная Туманским, уже была изображена Пушкиным. Своим стихотворением Туманский будто отвечает на пушкинский вопрос - взойдет ли «прекрасная заря» над «отечеством свободы просвещенной»:

Да отдохнет в свободе мир усталый;

Засейте вновь забытые поля,

На прошлое набросьте покрывало,

И песнями утешится земля.

\section{4. Заключение}

Стихотворение Туманского имеет утопический характер и воплощает мысль о «золотом веке», в противовес реальной действительности. Оно по проблематике и поэтическому языку включается в декабристскую поэзию. Дружеские отношения с Кюхельбекером Туманский поддерживал до трагических событий 1825 г. Таким образом, можно уверенно говорить, что Туманский не был поэтом «чистого искусства», он активно 
участвовал в общественной жизни 20-х гг. ХІХ в. О его отношениях с К.Ф. Рылеевым и кругом «Полярной звезды» мы расскажем в следующей статье.

\section{5. Благодарности}

Публикация подготовлена в рамках реализации ГЗ ЮНЦ РАН, № гр. проекта ААААA19-119011190182-8

\section{Литература}

Беляев, 1882 - Беляев А.П. Воспоминания декабриста о пережитом и перечувствованном (1805-1850). СПб.: Тип. А.С. Суворина, 1882. 507 с.

Браиловский, 1890 - Браиловский С. В.И. Туманский. Биографический и историколитературный очерк с приложением неизданных произведений поэта. СПб.: Пантеон литературы, 1890. Отд. оттиск. 48 с.

Вацуро, 1975 - Вацуро В. «Священный союз народов»// Литературное наследие декабристов. Л.: Наука, 1975. С. 265-280.

Вяземский, 1879 - Вяземский П.А. Полное собрание сочинений: в 2 т. Т. 2. СПб.: изд. гр. С.Д. Шереметева, 1879. 450 с.

Касаткина, 1987 - Касаткина В.Н. Поэзия гражданского подвига. Литературная деятельность декабристов. М.: Просвещение, 1987. 240 с.

Кюхельбекер, 1954 - Кюхельбекер В.К. Лекция о русской литературе и языке, прочитанная в Париже в 1821 г. // Декабристы-литераторы: Литературное наследство. Т. 59. KH. I. M.: AH CCCP, 1954. C. 345-380.

Кюхельбекер, 1967 - Кюхельбекер В.К. Избранные произведения: в 2 т. Т. 1. М.; Л.: Советский писатель, 1967. 666 с.

Мейлах, 1937 - Мейлах Б.С. Пушкин и русский романтизм. М.; Л.: Изд-во АН СССР, 1937. 293 c.

Нечкина, 1977 - Нечкина М.B. Грибоедов и декабристы. М.: Художественная литература, 1977. 735 с.

Тынянов, 1968 - Тынянов Ю. Французские отношения В.К. Кюхельбекера. Путешествие Кюхельбекера по Западной Европе // Тынянов Ю. Пушкин и его современники. М.: Наука, 1968. С. 295-329.

Туманский, 1819 - Туманский В.И. Письмо к издателю // Благонамеренный. 1819. № 23-24. C. 341-343.

Туманский, 1912 - Туманский В.И. Стихотворения и письма / Ред., биогр. очерк и примеч. Браиловского С.Н. СПб.: А.С. Суворин, 1912. 434 с.

Larionova, 2021 - Larionova M.Ch. The Forgotten Poet of the Pushkin Era. Part $1 / /$ Russkaya Starina. 2021. № 12(1). Pp. 13-19.

\section{References}

Belyaev, 1882 - Belyaev, A.P. (1882). Vospominaniya dekabrista o perezhitom i perechuvstvovannom (1805-1850) [Memoirs of the Decembrist about the experience and enumerated (1805-1850)]. SPb.: Tip. A.S. Suvorina, 507 p. [in Russian]

Brailovskii, 1890 - Brailovskii, S. (1890). V.I. Tumanskii. Biograficheskii i istorikoliteraturnyi ocherk s prilozheniem neizdannykh proizvedenii poeta [V.I. Tumanskij. Biographical and historical and literary essay with the application of unreleased works of the poet]. SPb.: Panteon literatury, Otd. ottisk. 48 p. [in Russian]

Kasatkina, 1987 - Kasatkina, V.N. (1987). Poeziya grazhdanskogo podviga. Literaturnaya deyatel'nost' dekabristov [Poetry of civil feat. Literary activities of the Decembrists]. M.: Prosveshchenie, 240 p. [in Russian]

Kyukhel'beker, 1954 - Kyukhel'beker, V.K. (1954). Lektsiya o russkoi literature i yazyke, prochitannaya v Parizhe v 1821 g. [Lecture on Russian literature and language, given in Paris in 1821]. Dekabristy-literatory: Literaturnoe nasledstvo [The Decembrists-Literalists: A Literary Heritage]. Vol. 59. Book. I. M.: AN SSSR, pp. 345-380. [in Russian]

Kyukhel'beker, 1967 - Kyukhel'beker, V.K. (1967). Izbrannye proizvedeniya: v 2 t. T. 1 [Selected works: In 2 vols. Vol. 1]. M.; L.: Sovetskii pisatel', 666 p. [in Russian] 
Larionova, 2021 - Larionova, M.Ch. (2021). The Forgotten Poet of the Pushkin Era. Part 1. Russkaja starina. 12(1): 13-19.

Meilakh, 1937 - Meilakh, B.S. (1937). Pushkin i russkii romantizm [Pushkin and Russian romanticism]. M.; L.: Izd-vo AN SSSR, 293 p. [in Russian]

Nechkina, 1977 - Nechkina, M.V. (1977). Griboedov i dekabristy [Griboedov and Decembrists]. M.: Khudozhestvennaya literatura, 735 p. [in Russian]

Tumanskii, 1819 - Tumanskii, V.I. (1819). Pis'mo k izdatelyu [Letter to Publisher]. Blagonamerennyi. 23-24: 341-343. [in Russian]

Tumanskii, 1912 - Tumanskii, V.I. (1912). Stikhotvoreniya i pis'ma. Red., biogr. ocherk i primech. Brailovskogo S.N. [Poems and letters. Editor, biographical sketch and notes by S.N. Brailovsky]. SPb.: A.S. Suvorin, 434 p. [in Russian]

Tynyanov, 1968 - Tynyanov, Yu. (1968). Frantsuzskie otnosheniya V.K. Kyukhel'bekera. Puteshestvie Kyukhel'bekera po Zapadnoi Evrope [French relations V.K. Kjuhel'beker. Kjuhel'beker's journey to Western Europe]. Tynyanov, Yu. Pushkin i ego sovremenniki [Pushkin and his contemporaries]. M.: Nauka, pp. 295-329. [in Russian]

Vatsuro, 1975 - Vatsuro, V. (1975). «Svyashchennyi soyuz narodov» [“The Holy Union of Peoples"]. Literaturnoe nasledie dekabristov [Literary Heritage of the Decembrists]. L.: Nauka, pp. 265-280. [in Russian]

Vyazemskii, 1879 - Vyazemskii, P.A. (1979). Polnoe sobranie sochinenii: v 2 t. T. 2 [Complete collected works: In 12 vols. Vol. 2]. SPb.: izd. gr. S.D. Sheremeteva, 450 p. [in Russian]

\section{Забытый поэт пушкинской эпохи. Часть 2}

Марина Ченгаровна Ларионова а ${ }^{\text {, * }}$

${ }^{a}$ Федеральный исследовательский центр Южный научный центр Российской академии наук, Российская Федерация

Аннотация. Долгое время В.И. Туманского считали исключительно элегическим поэтом. Однако Туманский был активным участником литературной жизни 20-30-х гг. $\mathrm{XIX}$ в. и состоял в дружеских отношениях с будущими декабристами. Пребывание во Франции, близость к французской интеллигенции способствовали становлению общественно-политических взглядов Туманского. Во время европейского путешествия он сблизился с В.К. Кюхельбекером, который посвятил ему стихотворение «К Туманскому», позже переименованное на «К Ахатесу» и отразившее общее отношение поэтов к борьбе греков за независимость. Под влиянием Кюхельбекера, его известной лекции о русском языке, прочитанной в «Атенее», Туманский написал стихотворение «Священный союз народов», явившееся вольным переводом стихотворения Беранже «La Saint-Alliance des peuples». Основная идея стихотворения - объединение народов в противовес «Священному союзу» монархов. Близкой декабристам оказывается и антикрепостническая позиция Туманского. Стихотворение Туманского имеет утопический характер и воплощает мысль о «золотом веке», в противовес реальной действительности. Таким образом, можно уверенно говорить, что Туманский не был поэтом «чистого искусства», он активно участвовал в общественной жизни 20-х гг. XIX в.

Ключевые слова: Туманский, Кюхельбекер, «К Туманскому», «Священный союз народов», декабристы.

\footnotetext{
* Корреспондирующий автор

Адреса электронной почты: larionova@ssc-ras.ru (М.Ч. Ларионова)
} 